\title{
Hot Metal Pretreatment and Less Slag Refining in BOF $^{*}$
}

\section{Introduction}

In August, 1985, a new refining process (NRP), which consists of hot metal pretreatment and less slag operation in BOF, started its commercial operation at Fukuyama Works, Nippon Kokan K.K.

The purpose of this system is to decrease the flux consumption by using less slag refining and to reduce the ferro-manganese consumption by direct reduction of manganese ore in BOF. Hot metal is desiliconized by flux injection ${ }^{1)}$ at No. 2 BF runner and is dephosphorized in ladle at the newly installed station ${ }^{2)}$ in this process. Since start up, the equipment has been operating smoothly and the monthly output amounts 120000 to $130000 \mathrm{t}$.

\section{Hot Metal Pretreatment}

The outline of NRP is shown in Fig. 1.

\section{Desiliconization}

Desiliconization equipment was installed at the No. 2 BF casthouse. The feature of this system is the top injection method (TIM) to inject a desiliconization reagent into the hot metal in runner with the carrier air.

The expected results that the average silicon content after desiliconization is $0.08 \%$ and the hitting ratio for $\mathrm{Si}<0.15 \%$ is more than $90 \%$ are successfully achieved with TIM. Such results are also attributed to the low silicon operation of No. 2 BF, whose hot metal silicon level is as low as $0.25 \%$ at tapping.

\section{Dephosphorization}

Desiliconized hot metal is then dephosphorized by lime based flux in the transfer ladle. Burnt lime with fluorspar and mill-scale is top charged and gaseous oxygen is supplied with a top lance to keep the proper oxygen potential of top slag. Intensive stirring is ultimately important to dephosphorize the hot metal in this process. A half amount of burnt lime is injected with a submerged lance to improve stirring of both metal bath and top slag. As the results, an average phosphorus level of $0.012 \%$ is obtained.

\section{Less Slag Refining in BOF}

Because of the low phosphorus content of hot metal, decarburization and manganese ore reduction are the main purpose of BOF refining. Flux consumption can be reduced to as low as $4 \mathrm{~kg} / \mathrm{t}$. According to the manganese level of the product, 10 to $25 \mathrm{~kg} / \mathrm{t}$ of manganese ore is charged at the first stage of refining.

Nippon Kokan's Combined Blowing (NK-CB) system has its characteristics in controlling the decarburization reaction and slag chemistry suitable to manganese ore reduction. ${ }^{3)}$ For example, the quantity balance of top blown oxygen and stirring gas from bottom is precisely controlled to reduce the total iron oxide content in slag at the final stage of blowing. As the result, a high level of manganese yield, $65 \%$, can be attained to save a large amount of ferro-manganese alloy: end point manganese content reaches to $0.9 \%$ when 25 $\mathrm{kg} / \mathrm{t}$ of manganese ore is charged.

\section{REFERENCES}

1) R. Yamamoto et al.: Tetsu-to-Hagané, 71 (1985), S915; Trans. Iron Steel Inst. Jpn., 26 (1986), B91.

2) O. Yamase et al.: Tetsu-to-Hagané, 72 (1986), S215.

3) M. Kawakami et al.: Tetsu-to-Hagané, 72 (1986), S241.

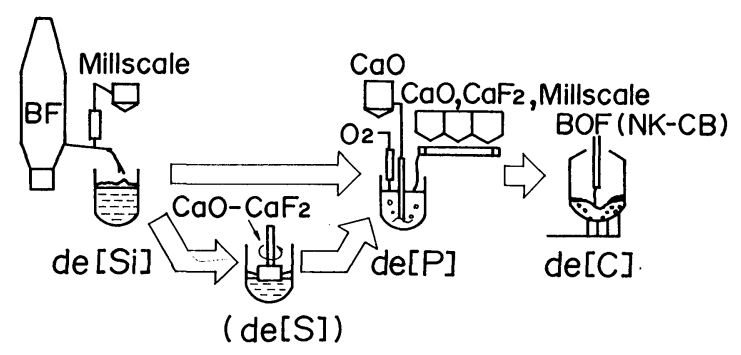

Fig. 1. Schematic flow of hot metal pretreatment.

\footnotetext{
* For further information, write to Primary Technology Department, Nippon Kokan K.K., 1-1-2, Marunouchi, Chiyoda-ku, Tokyo 100. (C) 1987 ISIJ
} 